\title{
ANÁLISE ESPAÇO-TEMPORAL DO DESMATAMENTO VIA SENSORIAMENTO REMOTO NO PROJETO DE ASSENTAMENTO SANTA JÚLIA, SUDOESTE DO ESTADO DO PARÁ
}

\author{
SPACE-TEMPORAL ANALYSIS OF DEFORESTATION VIA REMOTE SENSORING IN \\ SANTA JÚLIA SETTLEMENT PROJECT, SOUTHWEST OF PARÁ STATE
}

\author{
ANÁLISIS ESPACIO-TEMPORAL DE LA DEFORESTACIÓN VIA MONITOREO REMOTO \\ EN EL PROYECTO DE ASENTAMIENTO SANTA JÚLIA, SUDOESTE DEL ESTADO DE \\ PARÁ
}

\author{
Agnaldo Tremea ${ }^{1}$ \\ Juliano Gallo ${ }^{2}$ \\ Antônio José Ferreira Silva ${ }^{3}$
}

\begin{abstract}
Resumo
O desmatamento que ocorre no território amazônico, principalmente na região conhecida como "arco do desmatamento", resulta em alterações significativas na composição da superfície terrestre. Ferramentas de geoprocessamento e sensoriamento remoto gratuitas, em especial o QGIS e o Semi-automatic Classification Plugin (SCP), têm gerado produtos relevantes para o ordenamento territorial. Este artigo tem como objetivo delimitar o avanço do desmatamento no Projeto de Assentamento - PA Santa Júlia, no sudoeste do estado do Pará, considerando os anos de 1998, 2008 e 2018. Foram utilizadas imagens provenientes dos satélites LANDSAT 5 e LANDSAT 8 e, como resultado, produziram-se mapas temáticos explicitando que, neste intervalo de 20 anos, a área de floresta diretamente convertida em uso agropecuário passou de 0,28\% para 59,57\%. Atribui-se o aumento sobretudo ao aspecto logístico, um dos principais vetores do desmatamento na Amazônia.
\end{abstract}

Palavras-chave: Geoprocessamento. Desmatamento. SCP.

\begin{abstract}
The deforestation that occurs in the Amazonian territory, especially in the region known as the "deforestation arc", results in significant changes in the composition of the earth's surface. Free geoprocessing and remote sensing tools, in particular the QGIS and the Semi-automatic Classification Plugin (SCP) plugin, have generated relevant products to land use planning. This article aims to delimit the progress of deforestation in the Santa Júlia settlement project PA Santa Júlia, in the southwestern of Pará state, considering the years 1998, 2008 and 2018. LANDSAT 5 and LANDSAT 8 images were used and as a result, thematic maps explaining that, in this 20-year period, the area directly converted from forest to agricultural use rose from $0.28 \%$ to $59.57 \%$. The increase is mainly attributed to the logistic aspect, one of the main vectors of deforestation in the Amazon.
\end{abstract}

Keywords: Geoprocessing. Deforestation. SCP.

\section{Resumen}

La deforestación que ocurre en el territorio amazónico, principalmente en la región conocida como el "arco de la deforestación", resulta en alteraciones significativas en la composición de la superficie terrestre. Herramientas de geoprocesamiento y monitoreo remoto gratuitas, en especial el QGIS y el Semi-automatic Classification Plugin (SCP), han generado productos relevantes para el ordenamiento del territorio. Este artículo tiene como objetivo delimitar el avance de la deforestación en el Proyecto de Asentamiento - PA Santa Júlia, en el sudoeste del estado de Pará, tomándose en consideración los años 1998, 2008 y 2018. Se utilizaron imágenes provenientes de los satélites LANDSAT 5 y LADSAT 8 y, como resultado, se elaboraron mapas temáticos para explicitar que, en ese intervalo

\footnotetext{
${ }^{1}$ Eng. Agrônomo, Perito Federal Agrário (INCRA SR-30). E-mail: agnaldo.tremea@ sta.incra.gov.br.

${ }^{2}$ Mestre em Ciências Ambientais. E-mail: pontual.agriprecision@gmail.com

${ }^{3}$ E-mail: antonio.ferreira@sta.incra.gov.br
} 
de 20 años, el área de floresta directamente transformada en uso agropecuario pasó de 0,28\% a 59,57\%. El aumento se atribuye sobre todo al aspecto logístico, uno de los principales vectores de la deforestación en la Amazonia.

Palabras-clave: Geoprocesamiento. Deforestación. SCP.

\section{Introdução}

A ação antrópica sobre ecossistemas naturais, quando não regrada, gera impactos de grande magnitude. A busca por alimentos, água doce, combustíveis fósseis, madeiras e fibras, foi amplificada nas últimas décadas e vem causando transformações ambientais sem precedentes.

Para o ano de 2018, documentou-se cerca de $2.744 \mathrm{~km}^{2}$ de desmatamento somente no estado do Pará, indicando um aumento de $12,78 \%$ em relação ao ano de 2017 . Tal posição fica acima do incremento total no território amazônico para o mesmo período, que foi de 8,48\% (BRASIL, 2020a).

Mesmo assim, o Brasil é um dos poucos países com grande estoque de florestas tropicais passíveis de conversão para exploração agropecuária. Segundo Ferreira Filho, Ribera e Horridge (2015), tradicionalmente, a ocupação do solo pela agricultura no Brasil tem como etapa intermediária a passagem de florestas para pastagens.

Em um contexto de mudanças globais, o levantamento de cobertura da terra fornece subsídio para as análises e avaliações dos impactos, em especial, relacionados ao desmatamento. Neste sentido, mapas com a discriminação de categorias são componentes importantes para interpretação, análise e registro de observações da paisagem (BRASIL, 2013).

Através do sensoriamento remoto é possível a obtenção de grande acervo de informações espaciais sobre um determinado objeto na superfície terrestre. Com o estudo de dados gerados por satélites e seus sensores, é praticável o acesso, a classificação e análise via mapas temáticos, que facilitam a compreensão e identificação de feições terrestres. Segundo Novo (1998), o Sensoriamento Remoto consiste na aquisição e conversão da energia refletida por feições ou fenômenos em sinal passível de registro e apresentação adequada.

A elaboração de mapas temáticos através do uso de técnicas de geoprocessamento pode demandar alto custo, o que tem aumentado a procura por tecnologias livres e gratuitas (PEREIRA; GUIMARÃES; OLIVEIRA, 2018).

Desenvolvido pela National Aeronautics and Space Administration (NASA), no final da década de 60, o programa Land Remote Sensing Satellite (LANDSAT), objetiva, através 
de satélites e sensores acoplados, coleta de dados sobre os recursos naturais renováveis e não renováveis da superfície terrestre (NASA, 2019).

Composto por uma série de ferramentas especializadas em adquirir, armazenar, recuperar, transformar e emitir informações espaciais, o QGIS é um Sistema de Informações Geográficas composto por uma série de recursos, o qual possibilita uma grande diversidade de análises espaciais através de interface intuitiva, além da constante inclusão de novos complementos e ferramentas (CONGEDO, 2016).

O Semi-automatic Classification Plugin (SCP) é um complemento associado ao QGIS e que faz a classificação supervisionada/semiautomática de imagens multiespectrais provenientes de sensoriamento remoto. Fornece um conjunto de ferramentas de download, pré e pós-processamento, a fim de facilitar a classificação da cobertura da superfície terrestre (CONGEDO, 2016).

O objetivo deste trabalho foi delimitar o avanço do desmatamento no Projeto de Assentamento (PA) Santa Júlia, no sudoeste do estado do Pará, considerando os anos de 1998, 2008 e 2018, via recursos e ferramentas de geoprocessamento livres. Esta informação é de suma importância para a aplicação e fiscalização de políticas públicas, tanto do ponto de vista ambiental quanto ocupacional.

\section{Metodologia}

O PA Santa Júlia foi criado pelo Instituto Nacional de Colonização e Reforma Agrária, através da Portaria nº 68 de 07/10/1997 (BRASIL, 1997). Delineado inicialmente para atender a 300 unidades familiares de exploração agropecuária, compreende área georreferenciada de 28.334,57 hectares, incluindo Reserva Legal coletiva de 5.349,72 ha.

O projeto situa-se próximo à confluência entre os municípios de Novo Progresso, Itaituba e Altamira. Cerca de $97 \%$ do território fica confinado no primeiro município, do qual dista cerca de $77 \mathrm{~km}$ ao norte da sede, sentido BR-163. O restante do território analisado pertence ao município de Itaituba (Figura 01).

Está incluso na área conhecida como "Arco do Desmatamento", extensão que vai do sudeste do estado do Maranhão, ao norte do Tocantins, sul do Pará, norte de Mato Grosso, Rondônia, sul do Amazonas e sudeste do estado do Acre. Esta contempla uma das principais frentes de expansão da fronteira agropecuária (FERREIRA, VENTICINQUE; ALMEIDA, 2005). 
Figura 1: Localização da área em estudo.

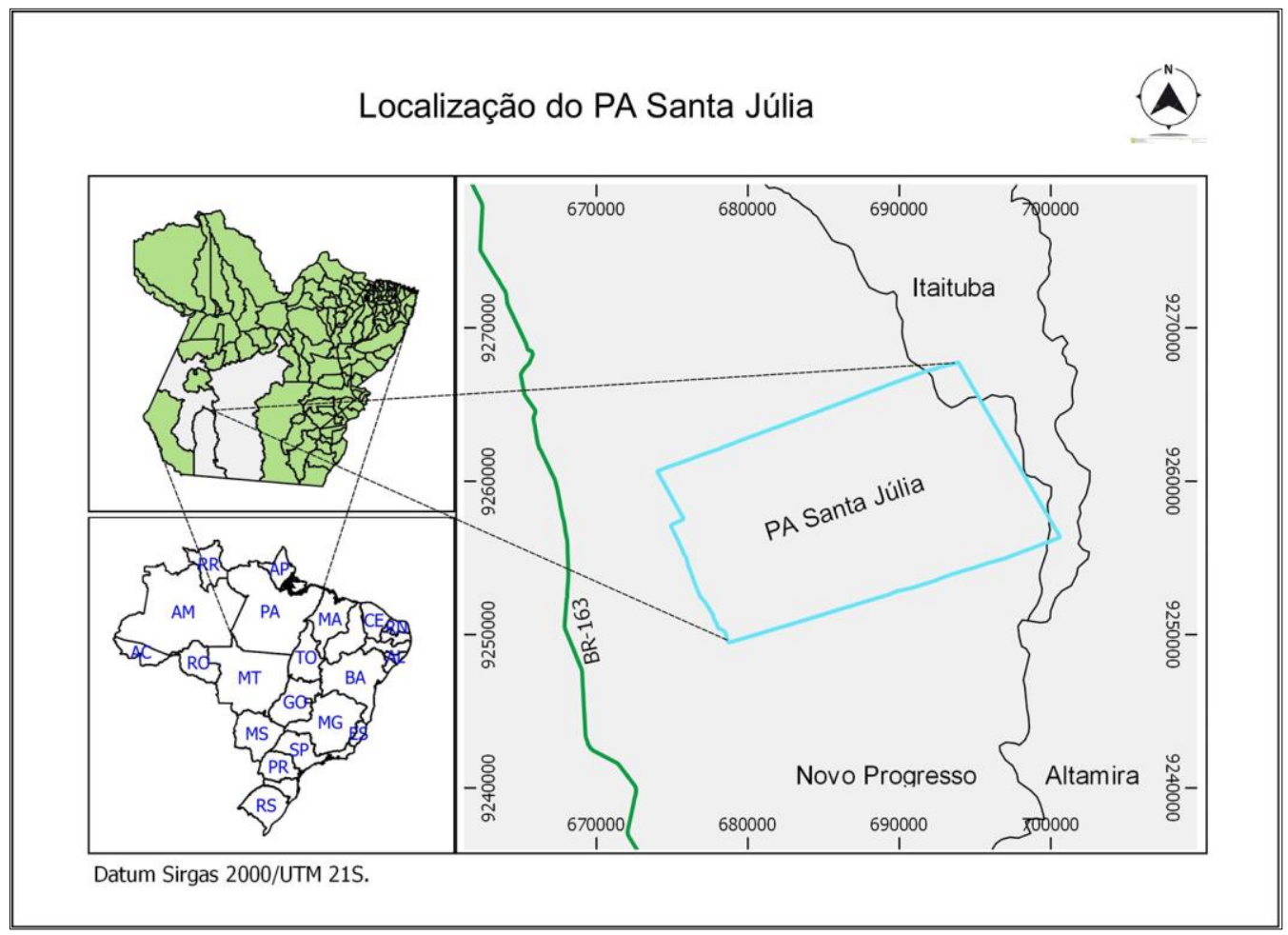

Fonte: o autor.

A atividade econômica prevalecente é a pecuária extensiva, a qual também tem grande importância econômica nas cidades do entorno.

A região é caracterizada pela predominância de floresta ombrófila densa de terra firme e clima equatorial. A temperatura e umidade relativa médias, respectivamente, são de $25.8^{\circ}$ C e $87 \%$. Já a precipitação média anual é de $1.982 \mathrm{~mm}$, concentrados principalmente nos meses de setembro a maio (BRASIL, 2020b).

As cenas foram obtidas gratuitamente no United States Geological Survey (USGS, 2019). A escolha foi determinada pela baixa ocorrência de nuvens, e se manteve um intervalo de dez anos entre os elementos a serem avaliados (Quadro 01).

A versão L8 possui atributos mais modernos, a exemplo do sensor OLI e da resolução radiométrica de 16 bits, frente ao L5, o qual dispõe do sensor TM e resolução radiométrica de 8 bits. Apesar disso, certa semelhança lhes é atribuída por fazerem parte de um mesmo grupo de satélites e apresentarem resolução temporal, espacial e espectral compatíveis, além de mesma área de imageamento. 
Quadro 01: Cenas utilizadas no processamento

\begin{tabular}{c|l|r|r}
\hline Satélite & \multicolumn{1}{|c|}{ Sensor } & Órbita/ponto & Data da passagem \\
\hline LANDSAT 5 (L5) & Thematic Mapmer (TM) & $227 / 065$ & $30 / 07 / 1998$ \\
\hline LANDSAT 5 (L5) & Thematic Mapmer (TM) & $227 / 065$ & $25 / 07 / 2008$ \\
\hline LANDSAT 8 (L8) & Operational Land Imager (OLI) & $227 / 065$ & $05 / 07 / 2018$ \\
\hline
\end{tabular}

Fonte: o autor.

Já os dados vetoriais da área em estudo foram adquiridos na base do Sistema de Cadastro Ambiental Rural (PARÁ, 2019).

O processamento foi realizado no QGIS versão 2.18 - Las Palmas, licenciado pela General Public Licence, através do complemento SCP versão 5.4.2, seguindo as orientações gerais de seu desenvolvedor (CONGEDO, 2016).

O conjunto de imagens foi submetido ao método Dark Object Subtraction (DOS1), o qual promove a correção atmosférica, ao considerar as características meteorológicas no momento da aquisição da imagem. Na sequência, foi criado um Band set, o que permitiu facilidade em compor a imagem com diferentes combinações de forma rápida.

A composição mais satisfatória se deu na sequência de bandas espectrais R4, G3 e B2 para o satélite L5 e R5, G4 e B3 para o satélite L8. Este arranjo é tido como de falsa cor, pois usa informações espectrais além da percepção do olho humano. Ambos correspondem às bandas representativas do infravermelho próximo $(0,76-0,90 \mu \mathrm{m})$, vermelho $(0,63-0,69$ $\mu \mathrm{m})$ e verde $(0.52-0.60 \mu \mathrm{m})$. A combinação RGB escolhida também foi usada por outros autores (PAULA; PEREIRA; MARTINS, 2012; OLIVEIRA; COSTA; RIBEIRO, 2017).

Em seguida, foram indicados os vetores de armazenamento das Regions Of Interest ou Áreas de Treinamento, os quais se prestaram como fator de calibragem para classificação supervisionada para as duas classes de uso definidas: "Floresta" e "Uso agropecuário". Frente à resolução e escala propostas, não foi satisfatória a identificação de corpos hídricos de relevância.

Pontos representativos, marcados com GPS no perímetro deste estudo, serviram de base para orientar a seleção das Áreas de Treinamento. Para auxiliar neste processo de triagem, também foram utilizados parâmetros físicos de identificação contidos nas imagens, como forma, tamanho, tonalidade, disposição, entre outros.

O algoritmo geoestatístico de classificação da área utilizado foi o Maximum Likelihood. Paralelo à classificação de toda a área de interesse, foi realizada a vetorização, a qual converte a 
camada composta raster para o formato vetorial, possibilitando separar e quantificar as diferentes feições, as quais foram posteriormente usadas na elaboração dos mapas.

A fim de verificar os dados levantados, foi gerada uma Matriz de Confusão para a estimativa da acurácia da classificação gerada com o SCP, a qual serviu de base para o cálculo da Exatidão Global e do Índice Kappa.

A Exatidão Global divide o total de pixels classificados corretamente (diagonal da matriz) pelo número total de pixels da matriz. Já o Índice Kappa leva em consideração toda a Matriz de Confusão no seu processamento (CONGALTON, 1991). Segundo Landis e Kock (1977 apud BATISTA; LEAL SANTOS, 2011), este índice pode ser classificado de Quase inexistente a Excelente (Tabela 01).

Tabela 01: Qualidade da classificação associada aos valores do Índice Kappa

\begin{tabular}{l|l}
\hline \multicolumn{1}{c|}{ Índice Kappa } & \multicolumn{1}{c}{ Interpretação/concordância } \\
\hline$<0,00$ & Quase inexistente \\
\hline $0,00-0,20$ & Insignificante \\
\hline $0,20-0,40$ & Discreto \\
\hline $0,40-0,60$ & Moderado \\
\hline $0,60-0,80$ & Substancial \\
\hline $0,80-100$ & Excelente \\
\hline
\end{tabular}

Com os recortes classificados e vetorizados, através da ferramenta Classification sieve, foram eliminados os ruídos, ou seja, porções de pequeno tamanho que não representam a realidade. Para tanto, áreas menores que 70 pixels foram incorporadas pelo valor de pixel de área vizinha de maior magnitude, sem prejuízo à qualidade do resultado.

O relevo sombreado foi elaborado a partir de dados do Modelo Digital de Elevação Shuttle Radar Topography Mission (SRTM Topodata), adquirido no Banco de Dados Geomorfométricos do Brasil (BRASIL, 2019a) e o Sistema de Referência de Coordenadas do mosaico foi projetado em coordenadas planas, Universal Transversa de Mercator (UTM) com Datum Sirgas 2000.

\section{Resultados e discussões}

Realizada a análise dos elementos representativos do espaço temporal, foi possível dimensionar e espacializar as alterações sobre a vegetação nativa no PA Santa Júlia. 
As imagens geradas pela família de satélites LANDSAT são tidas como de média resolução e grande valor lhes é atribuído pelo importante acervo histórico. Através dos testes estatísticos e comparativos ficou demonstrada a eficiência dos recursos utilizados na quantificação e qualificação de áreas desmatadas na área proposta.

Nas Figuras 02 a 04, as Matrizes de Confusão apresentam, entre outros, os valores de Exatidão Global (Overall accuracy) acima de 98,17\%. Já o Índice Kappa (Kappa hat classification) ficou acima de 0,94, resultado considerado excelente (Tabela 01).

Figura 02: Matriz de Confusão - 1998

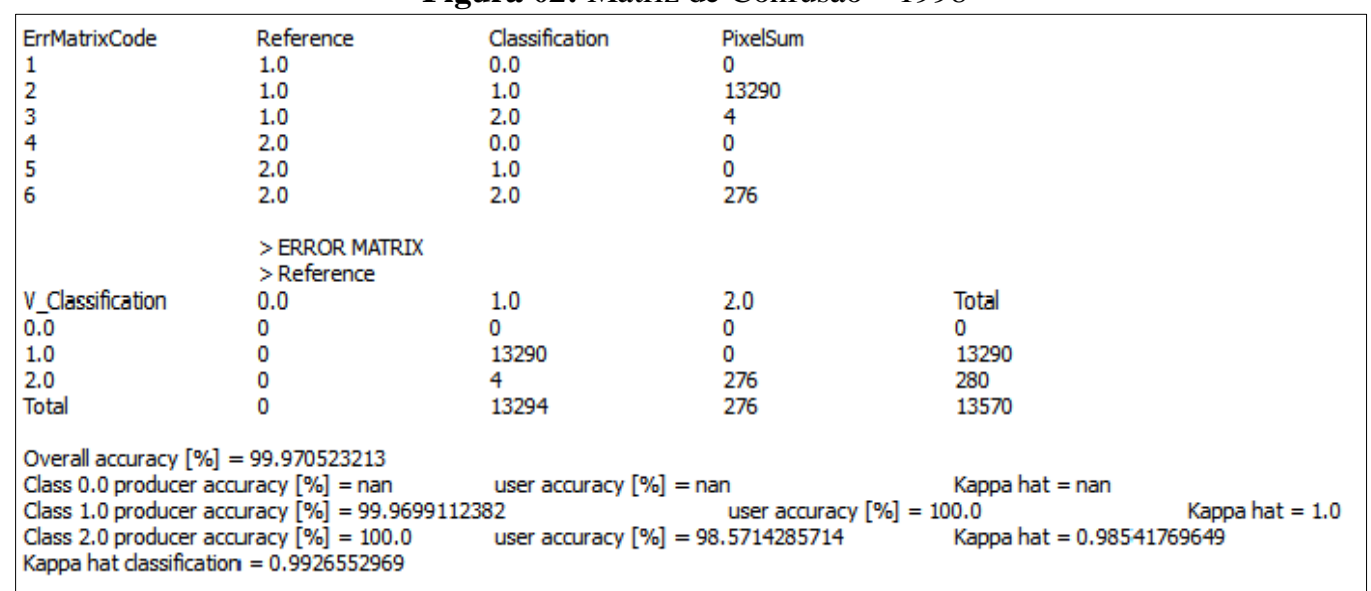

Fonte: o autor.

Figura 03: Matriz de Confusão - 2008

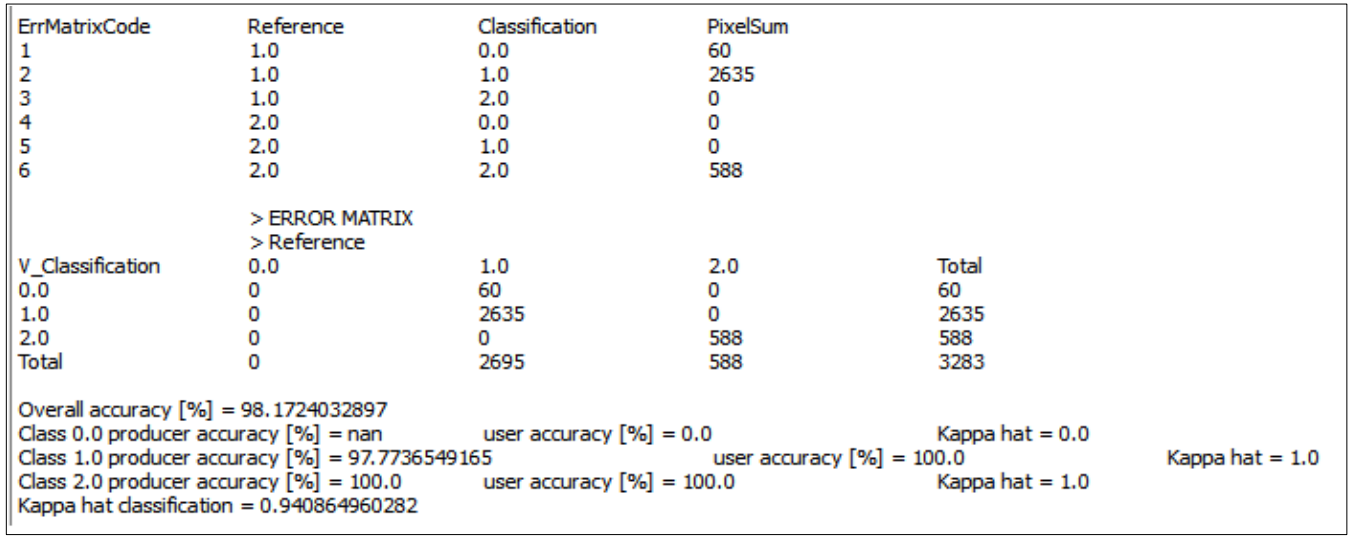

Fonte: o autor. 


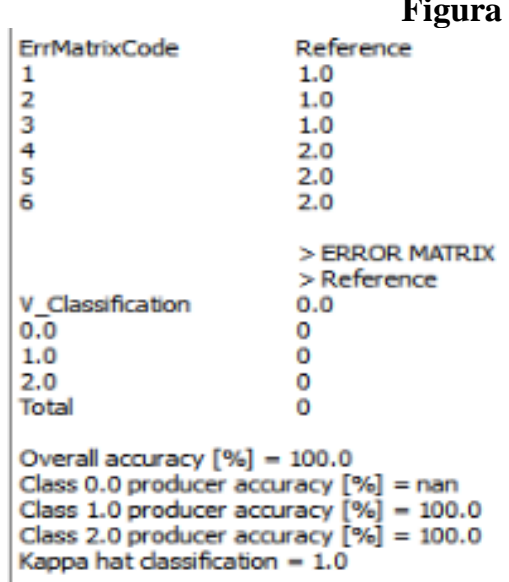

Figura 04: Matriz de Confusão - 2018

$\begin{array}{ll}\text { Classification } & \text { Pixelsum } \\ 0.0 & 0 \\ 1.0 & 638 \\ 2.0 & 0 \\ 0.0 & 0 \\ 1.0 & 0 \\ 2.0 & 3309\end{array}$

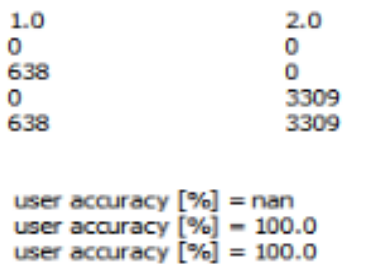

Total

638

3309
3947

Kappa hat $=$ nan Kappa hat $=$ nan Kappa hat $=1.0$

Fonte: o autor.

Observa-se que 80,01 ha encontravam-se desflorestados no momento da análise do ano de 1998, representando apenas cerca de 0,28\% do total da área (Figura 05). As duas pequenas áreas classificadas como "Uso agropecuário", situadas a oeste e sudoeste, em uma análise superficial da imagem de satélite composta, dão a impressão de estarem ligadas. Ocorre que com a classificação, foram gerados vários ruídos entre as feições, os quais foram eliminados pela ferramenta Classification sierve.

Uma particularidade ocorreu nesta avaliação: o plugin SCP classificou três feições como "Uso agropecuário", contornadas em azul no recorte ampliado, as quais juntas somam 21,81 ha (Figura 06). Estas foram posteriormente mescladas manualmente para a classe "Florestas" por não se tratarem de zonas diretamente antropizadas.

Figura 05: Ocupação do solo no PA Santa Júlia no ano de 1998.

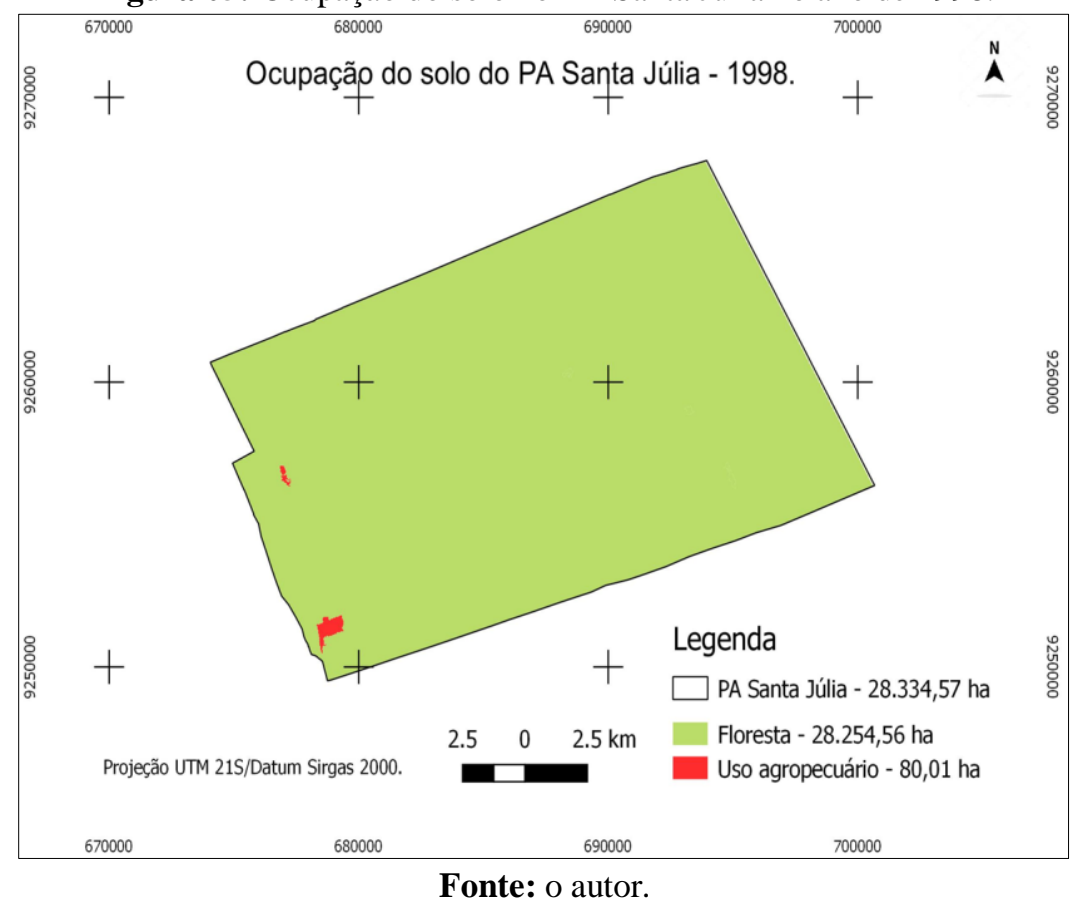


Figura 06: Relevo sombreado do PA Santa Júlia com feições mescladas (recorte ampliado) - 1998.

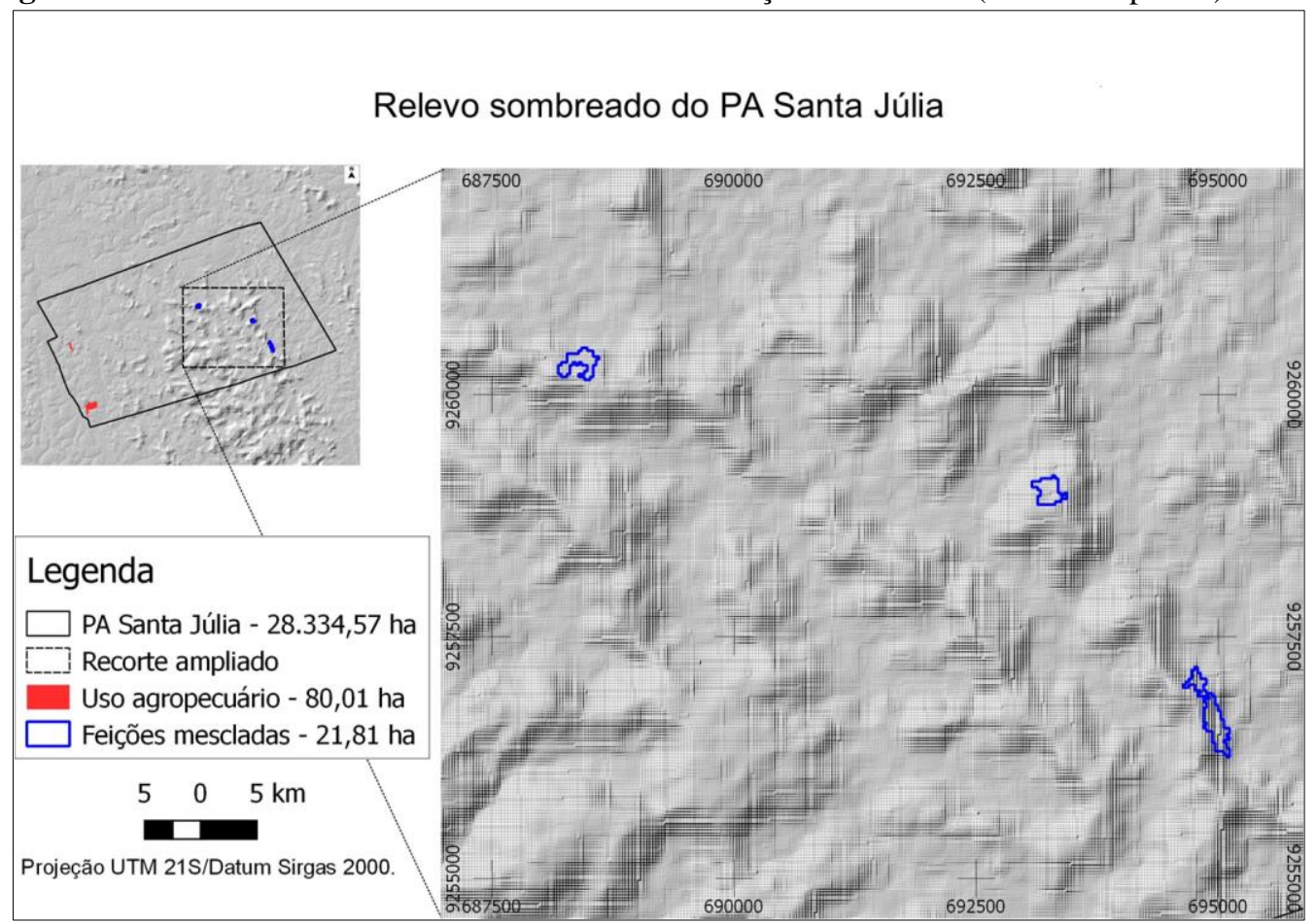

Fonte: o autor.

Através da análise deste recorte e seus elementos físicos — e associando o Modelo Digital de Elevação - , concluiu-se que estas zonas compreendem topos de morros e serras, apesar de apresentar assinatura espectral muito semelhante à pequena área realmente desmatada, situada na porção oeste e sudoeste (Figura 05). Na prática, estas áreas não se destinavam à exploração agropecuária ou madeireira naquele momento histórico.

Já para o ano de 2008, o índice de conversão aumentou para 28,8\%, ou seja, 8.160,39 ha. Nesta, percebe-se a delimitação das unidades de exploração individuais, bem como a abertura de vicinais, fruto das ações de implantação do projeto de assentamento (Figura 07).

Em 2018, este índice elevou-se a 59,57\%, portanto, $16.877,87$ ha de florestas encontravam-se convertidas em uso agropecuário, dos quais, 1.797,67 ha dentro do limite preestabelecido como Reserva Legal (Figura 08).

Por conseguinte, entre 2008 e 2018, houve um aumento de mais de $100 \%$ na área ocupada por práticas agropecuárias. Neste mesmo período, o aumento da área desmatada calculado para o estado do Pará e no município de Novo Progresso foi, respectivamente, pouco mais de $10 \%$ e $24 \%$ (BRASIL, 2019b).

O acentuado aumento do desmatamento da área em estudo em relação ao município e o estado, pode ser explicado pelo fato do PA Santa Júlia estar diretamente exposto a um dos principais vetores do desmatamento na Amazônia: o aspecto logístico. 
Figura 07: Ocupação do solo no PA Santa Júlia no ano de 2008

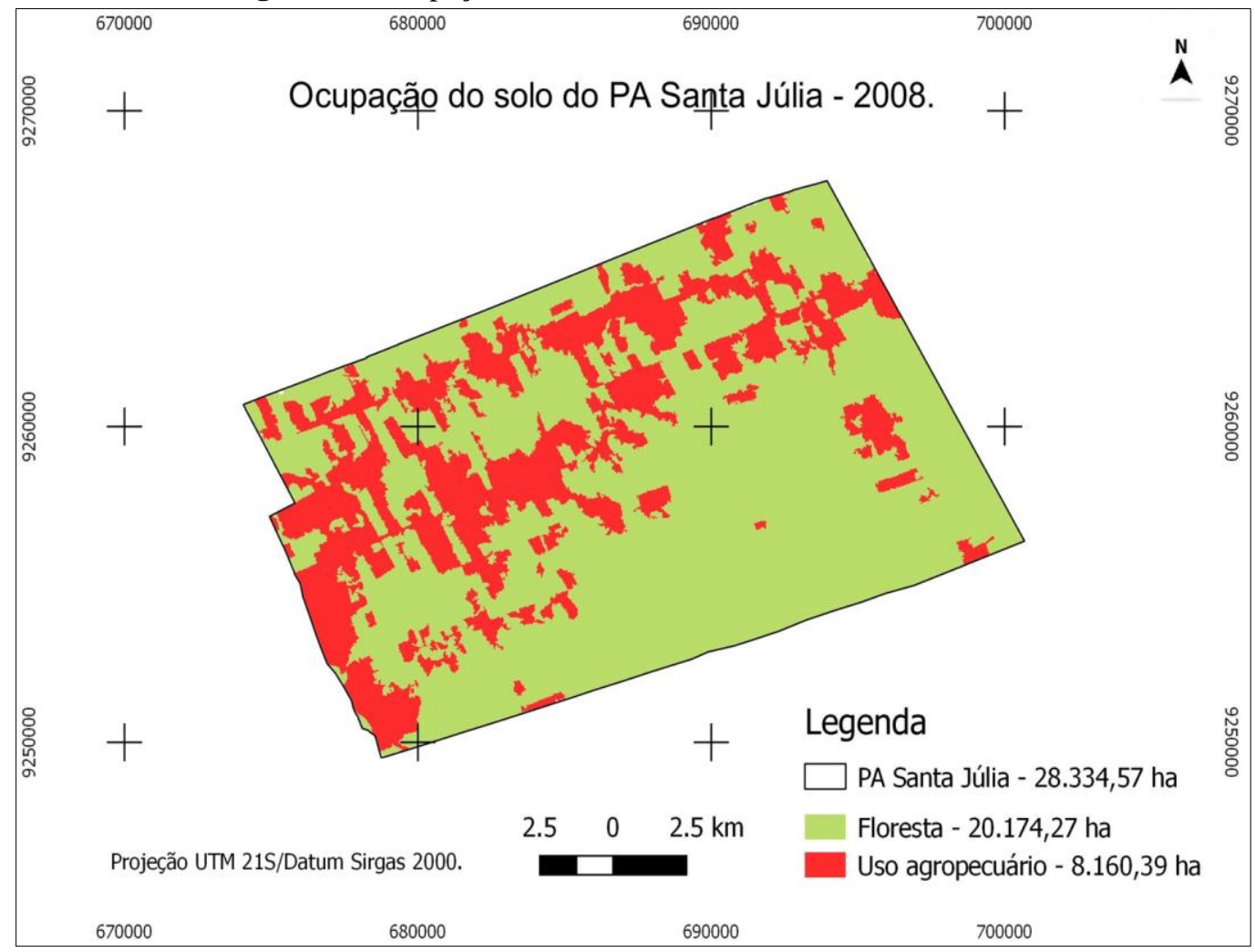

Fonte: o autor.

Figura 08: Ocupação do solo do PA Santa Júlia no ano de 2018

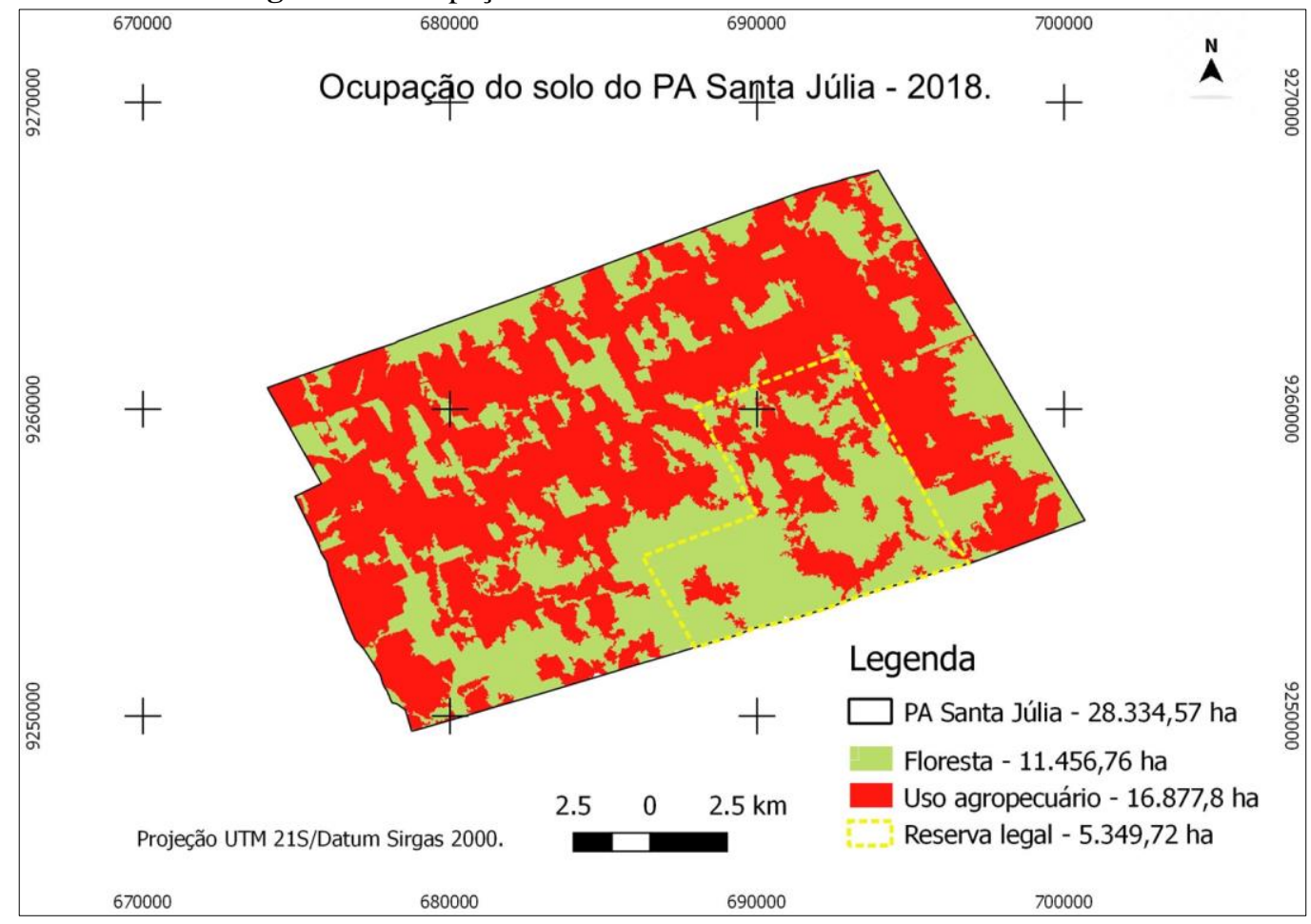

Fonte: o autor.

A região analisada dista cerca de $6 \mathrm{~km}$ da BR-163, rodovia que interliga longitudinalmente o país, além de possuir vicinais internas por conta da implantação do 
assentamento. Vários autores relacionam a ocorrência de estradas em áreas inicialmente de baixa ocupação, associada ao alto rendimento da extração de madeira e produção pecuária, como fatores de grande influência nos elevados índices regionais de desmatamento (MARGULIS, 2003; RIVERO; ALMEIDA, ÁVILA, 2009; FERREIRA FILHO; RIBERA; HORRIDGE, 2015; ALENCAR et al., 2016).

Em uma análise comparativa, o resultado do desmatamento acumulado nesta última análise ficou 4,83\% abaixo dos dados fornecidos pelo Programa de Cálculo do Desflorestamento da Amazônia - PRODES (BRASIL, 2019b). O sistema oficial identificou, após mesclagem das feições, que para o ano de 2018, cerca de 17.734,6 ha haviam sido desmatados (Figura 09).

Figura 09: Desmatamento calculado para o ano de $2018 \mathrm{x}$ dados fornecidos pelo PRODES para o mesmo

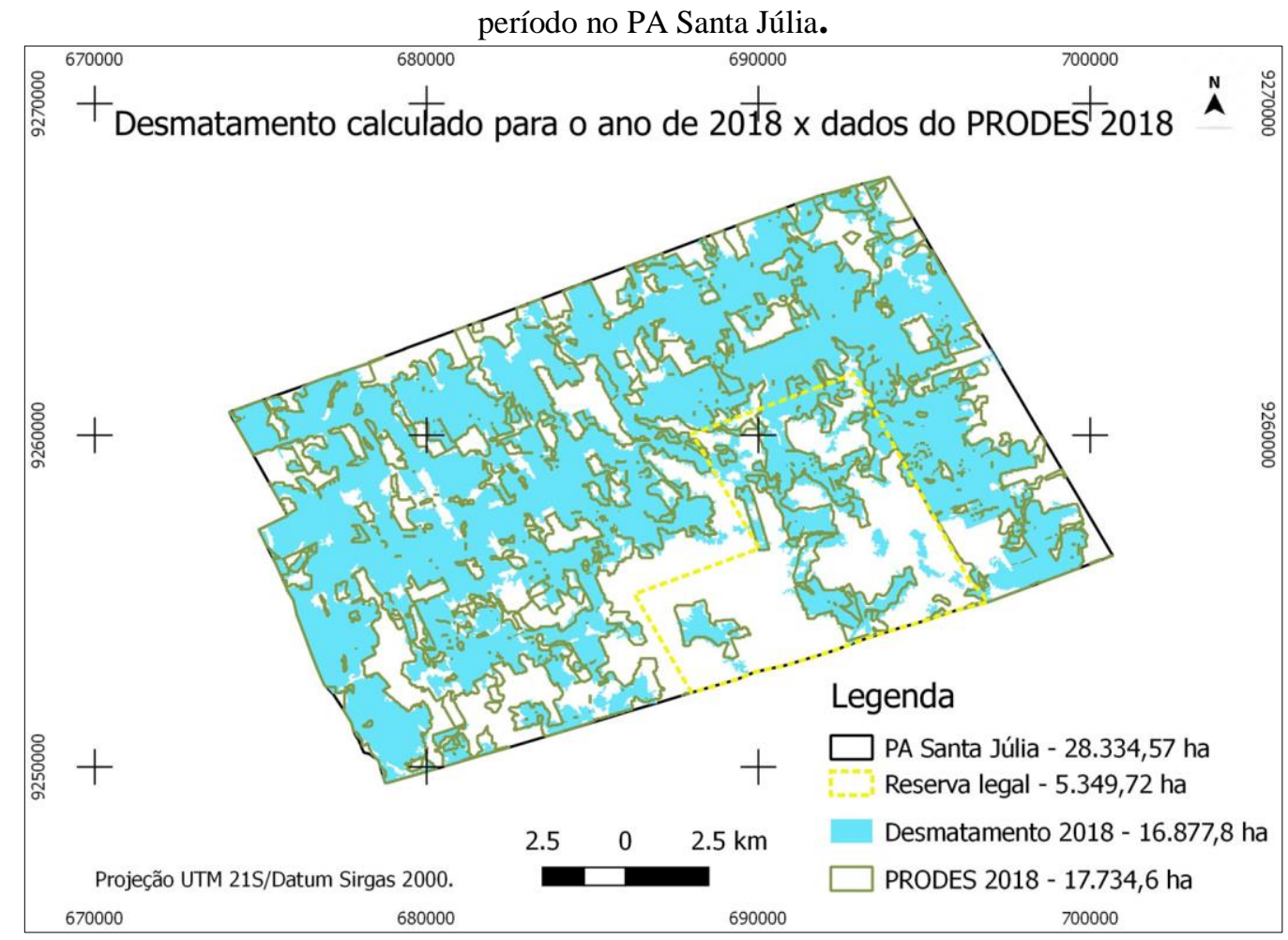

Fonte: o autor.

Esta diferença pode ser justificada pelo fato de o PRODES fazer uso de metodologia diferente, conforme documentado por Câmara, Valeriano e Soares (2006). Destaque dado pelo fato de que a coleta de dados se dá nos meses de julho, agosto e setembro, período com menor ocorrência de nuvens. Já a data da passagem do satélite sobre a área de interesse e que gerou a imagem que representa o desmatamento acumulado para o ano de 2018 (Figura 08), se deu no mês de julho (Quadro 01). Portanto, a diferença nas datas de coleta de dados referenciais pode ter influenciado no menor resultado de desmatamento encontrado neste trabalho. 
O fator subjetividade no processo de definição das Áreas de Treinamento da atividade proposta também atua diretamente no resultado final da classificação que, aliado à ocorrência de áreas de transição entre desmatamento e floresta, passando pela degradação florestal, impuseram certa dificuldade à delimitação correta das classes. Tais zonas intermediárias são resultado de prática que consiste no desbaste do sub-bosque e parte dos exemplares madeireiros dominantes, deixando algumas árvores esparsas com a finalidade de formar pastagens e dificultar a detecção por sistemas de monitoramento (COUTO; SAUSMIKAT, 2005).

\section{Considerações finais}

O SCP e os demais recursos utilizados cumpriram com o objetivo de classificar as cenas de referência. Diante dos resultados, reafirma-se a importância do sensoriamento remoto e o geoprocessamento como dispositivos auxiliares na gestão do uso e ocupação do solo. Resultados mais precisos podem ser obtidos a partir de imagens com alta resolução espacial.

De maneira auxiliar no processo de classificação supervisionada, sugere-se o uso de Modelos Digitais de Elevação. Este recurso foi essencial na identificação de feições que representam regiões de maior altitude, que possuem similaridade na assinatura espectral com áreas recém-desmatadas.

Recomenda-se aos órgãos gestores do PA Santa Júlia que os dados discutidos neste artigo sejam submetidos ao crivo dos instrumentos legais de proteção ambiental, principalmente em relação ao uso e ocupação do solo internamente ao perímetro da área demarcada como Reserva Legal.

\section{Referências}

ALENCAR, A.; PEREIRA, C.; CASTRO, I.; CARDOSO, A.; SOUZA, L.; COSTA, R.; BENTES, A. J.; STELLA, O.; AZEVEDO, A.; GOMES, J.; NOVAES, R. Desmatamento nos assentamentos da Amazônia: histórico, tendências e oportunidades. Brasília, DF: IPAM, 2016.

BATISTA, J. L. O; LEAL SANTOS, R, L. Análise da dinâmica do uso e ocupação da terra em pequenos municípios baianos do semiárido brasileiro: o caso de Teofilândia. Rev. Geogr. Norte Gd, Santiago, n. 49, p. 139-155, set. 2011. Disponível em: https://scielo.conicyt.cl/scielo.php?script=sci_arttext\&pid=S071834022011000200009\&lng=es\&nrm=iso. Acesso em: 01 jul. 2020.

BRASIL. Portaria $N^{\circ}$ 68, de 7 de outubro de 1997. Diário Oficial da União: seção 1, Brasília-DF, p. 22.543, 8 out. 1997. 
BRASIL. Instituto Brasileiro de Geografia e Estatística. Manual Técnico de Uso da Terra. 3. ed. Rio de Janeiro-RJ: IBGE, 2013.

BRASIL. Ministério da Ciência, Tecnologia Inovações e Comunicação. Instituto Nacional de Pesquisas Espaciais - INPE. Topodata. 2019a. Disponível em:

http://www.dsr.inpe.br/topodata/index.php. Acesso em: 20 fev. 2019.

BRASIL. Ministério da Ciência, Tecnologia, Inovações e Comunicação. Instituto Nacional de Pesquisas Espaciais - INPE. PRODES Digital. 2019b. Disponível em:

http://www.dpi.inpe.br/prodesdigital/. Acesso em: 09 jun. 2019.

BRASIL. Ministério da Ciência, Tecnologia Inovações e Comunicação. Instituto Nacional de Pesquisas Espaciais - INPE. PRODES. 2020a. Disponível em:

http://www.obt.inpe.br/OBT/assuntos/programas/amazonia/prodes. Acesso em: 31 jul. 2020.

BRASIL. Ministério da Ciência, Tecnologia Inovações e Comunicação. Instituto Nacional de Meteorologia - INMET. 2020b. Disponível em:

http://www.inmet.gov.br/portal/index.php?r=bdmep/bdmep. Acesso em: 31 jul. 2020.

CÂMARA, G; VALERIANO, D. M; SOARES, J. V. Metodologia para o cálculo da taxa anual de desmatamento na Amazônia Legal. São José dos Campos-SP: INPE, 2006.

CONGALTON, R. G. A review of assessing the accuracy of classifications of remotely sensed data. Remote Sensing of Environment, [S.l.], v. 49 n. 12, p. 1671-1678, 1991.

CONGEDO, L. Semi-automatic classification plugin documentation. 2016. Disponível em: https://media.readthedocs.org/pdf/semiautomaticclassificationmanual-

v5/latest/semiautomaticclassificationmanual-v5.pdf. Acesso em: 01 jul. 2019.

COUTO, C; SAUSMIKAT, A. H. Corte seletivo na Amazônia Legal. Perícia Federal, Brasília, ano 7, n. 21, maio/ago. 2005.

FERREIRA, L. V; VENTICINQUE, E; ALMEIDA, S. O desmatamento na Amazônia e a importância das áreas protegidas. Estudos Avançados, São Paulo, v.19, n. 53, p. 157-166, abr. 2005.

FERREIRA FILHO, J. B. S; RIBERA, L; HORRIDGE, M. Deforestation control and agricultural supply in Brazil. American Journal of Agricultural Economics, [S.l.], v. 97, n. 2, p. 589-601, mar. 2015.

MARGULIS, S. Causas do desmatamento da Amazônia Brasileira. 1. ed. Brasília-DF: Banco Mundial, 2003.

NASA. Administração Nacional do Espaço e da Aeronáutica (EUA). 2019. Disponível em: https://landsat.gsfc.nasa.gov/landsat-9/. Acesso em: 01 jul. 2019.

NOVO, E. M. L. M. Sensoriamento remoto: princípios e aplicações. 2. ed. São Paulo-SP: Editora Edgard Blücher, 1998. 
OLIVEIRA, M, A, P; COSTA, V, C; RIBEIRO, M, F. Análise do uso do solo na Área de Proteção Ambiental Suruí, Magé - RJ, com base em classificação supervisionada de imagem Landsat 8. In: SIMPÓSIO BRASILEIRO DE SENSORIAMENTO REMOTO -SBSR, 13., 2017, Santos. Anais [...]. Santos-SP: INPE, 2017.

PAULA, M. R; PEREIRA, J. B; MARTINS, A. P. Uso de técnicas de sensoriamento remoto e geoprocessamento na caracterização do uso da terra da bacia hidrográfica da HUE Caçu-GO.

Revista Geonorte, Manaus, ed. esp., v. 3, n. 6, p. 127-139, jun. 2012.

PARÁ. Secretaria de Estado de Meio Ambiente e Sustentabilidade - SEMAS. Sistema de Cadastro Ambiental Rural do Estado do Pará - SICAR. 2019. Disponível em: http://car.semas.pa.gov.br/\#/. Acesso em: 15 abr. 2019.

PEREIRA, L.F; GUIMARÃES, R. M. F; OLIVEIRA, R. R. O. Integrando geotecnologias simples e gratuitas para avaliar usos/coberturas da terra: QGIS e Google Earth Pro. Journal of Environmental Analysys and Progress, Recife, v. 3, n. 3, p. 250-264, 2018.

RIVERO, S.; ALMEIDA, O.; ÁVILA, S.; OLIVEIRA, W. Pecuária e desmatamento: uma análise das principais causas diretas do desmatamento na Amazônia. Revista Nova Economia, Belo Horizonte, vol. 19, n. 1, p. 41-66, jan/abr. 2009.

USGS. Serviço Geológico dos Estados Unidos (EUA). 2019. Disponível em: https://earthexplorer.usgs.gov/. Acesso em: 15 abr. 2019. 